\title{
Effect of milk replacer added Macleaya cordota extract calf body weight and health*
}

\author{
Research Article \\ Volume: 3, Issue: 2 \\ August 2019 \\ Pages: $32-36$
}

\section{Irmak Şaştır Köroğlu ${ }^{1}$ Neşe Kocabağlı ${ }^{2}$}

\begin{abstract}
1. ANC Animal Nutrition Company Address: Soğanlık Esentepe Mah. Cevizli D100 Güney Yanyol No: 25/144 Kartal, Istanbul/ Turkey. 2. Istanbul University-Cerrahpaşa, Faculty of Veterinary Medicine, Department of Animal Nutrition and Nutritional Diseases, 34320 Avcilar, İstanbul/Turkey.
\end{abstract}

Irmak Şaştır Köroğlu ORCID: 0000-0002-0205-9079, Neşe Kocabağlı ORCID: 000-0002-2797-9410

\section{Article History}

Received: 20.05.2019

Accepted: 08.07.2019

Available online:

12.07.2019

\begin{abstract}
This experiment was conducted on 40 newborn Holstein female calves comprising two experimental groups, with 20 calves in each group to investigate the effects of Macleaya cordata extract (MCE), on calf body weight and health which added to milk replacer. In both group calves fed on the same terms. Differently, $10 \mathrm{~g} / \mathrm{head} /$ day dosages MCE added to the milk replacer of the trial group from day 3 to day 25. Afterward, calves continued to feed until 3 months old and weighed on the birth, 15th, 40th, 60th and 90th days. At the end of the experiment, there was no significant difference at the weights on the birth and 15th days. However, on the 40th, 60th and 90th days weighing in favor of the control group, a significant difference was found $(P<0.05)$. At the end of the experiment in favor of the trial group, there was a significant difference with clinical pneumonia and aspiration pneumonia $(P<0.05)$. The results obtained in the research; MCE which added the milk replacer as a feed additive indicated no positive effect on calf body weight. From a health point of view, MCE has reduced the incidence of respiratory diseases in particular.
\end{abstract}

Keywords: calf, phytobiotic, performance, respiratory disease

\section{*This article is summarized from the master thesis of the first author}

DOI: $10.30704 / \mathrm{http}-w w w-j i v s-n e t .568061$

To cite this article: Köroğlu, I. Ş ., Kocabağlı N. (2019). Effect of milk replacer added Macleaya cordota extract calf body weight and health. Journal of Istanbul Veterinary Sciences. 3(2), 32-36, Abbreviated Title: J Ist Vet Sci

\section{Introduction}

During the past decades, there were renewed interest in developing natural compounds and understanding their target specificity for drug development instead of antibiotics. The recent demand for reduction of antibiotic use in animal production and the ban on their use as feed additives in the European Union (Regulation 1831/2003/ EC), has led to the development and evaluation of alternatives for improving animal performance and health status.
Plant-derived natural bioactive compounds have a large variety of active ingredients and thus represent one of the most promising alternatives to antibiotics. However, the results from these studies have largely been inconsistent and the mechanisms are still inconclusive with limited resources (Liu et al. 2014). For example; gradual or suddenly weaned calves were fed essential oils blend (EOB) as feed additives, results showed that EOB had the potential to improve growth 
performance and to decrease the effect of stressful events in suckling calves (Jeshari et al., 2016). In contrast to this, oregano oil extract did not affect performance and blood parameters in lambs (Ünal and Kocabağlı, 2014). Macleaya cordata extract (MCE) is of great scientific and practical interest to researchers, due to its antimicrobial and antiinflammatory responses within experimental animals (Newton et al., 2002). This extract has a natural appetite enhancer effect on swine, cattle, poultry and even aquaculture (Vieira et al., 2008). MCE is a natural plant-derived (Sangrovit ${ }^{\circledR}$ ) supplement, standardized the weight to $1.5 \%$ as used in animal nutrition, containing manybenzophenanthidrine alkaloid compounds, the most abundant of which is sanguinarine (Dvǒŕak et al., 2006). Antimicrobial (Namkung et al., 2004; Walker et al., 1990), antifungal, immunomodulator (Chaturvedi et al., 1997) and anti-inflammatory (Namkung et al., 2004; Yui et al., 1993) effects were determined in different studies.

Many studies in poultry (Vieira et al., 2008; Matulka et al., 2018), beef cattle (Aguilar Hernández et al., 2016) and pigs (Kantas et al., 2015; Liu et al., 2016; Zhao, et al., 2017) has been reported positive effect of sanguinarine-like alkaloids on performance. A Study conducted especially in piglet extract of MCE has been reported as an alternative to antibiotics with diarrhea prevention and a positive effect on immunity (Liu et al., 2016). There are no reported studies on the use of the MCE as feed additives in Turkey until today. Thus, the aim of this study was to examine the effect of Macleaya cordata extract on calf body weight and health which added to milk replacer.

\section{Materials and methods}

This research project was conducted at Uluova Dairy Farm (in Ezine, Çanakkale/Turkey) from September 2017 to January 2018; all procedures were approved by Çanakkale 18 Mart University Animal Experiments Local Ethics Committee (decision number: 2017 / 0801). In the study, 40 female Holstein calves were used which has born in the date between SeptemberOctober 2017 and selected calves considering the weights and divided into two groups for the experiment.

The first three days, calves were fed with colostrum, then they transferred to the individual boxes and fed with milk and milk replacer mixture (mixture content $50 \mathrm{~g}$ of commercial milk replacer with 2 liters of milk) and fed with 3 times a day. Calves had free access to calf starter feed + roughage + corn flakes mixture and fresh water all times during the trial. A total of $2.5 \mathrm{~kg}$ of this mixture formed by $200 \mathrm{~g}$ chopped alfalfa hay, $500 \mathrm{~g}$ corn flakes and, $1800 \mathrm{~g}$ calf starter feed. This mixture was prepared and given every day to the animals in front of their individual boxes. We added $10 \mathrm{~g} /$ head/ day dosage MCE (Sangrovit ${ }^{\circledR} \mathrm{CS}$, Phytobiotics Futterzusatztoffe $\mathrm{GmbH}$, Rosengasse9, 65343 Eltville, Germany) in milk and milk replacer mixture to the trial group. This process adds it into the morning feeding. In conclusion; Macleaya cordata extract added for 3 weeks to the trial group.

The label information of the milk replacer which is used in research (Halavit 440, Maabarot Products Ltd., Post Maabarot 4023000, Israel) contains Crude protein $23 \%$, Casein $16 \%$, Crude Fat $15 \%$, Crude Ash $7 \%$, Crude Cellulose $0.05 \%$, Sodium $0.5 \%$. This milk replacer mixed in 2 liters milk with $50 \mathrm{~g}$ dosage milk replacer.

During the research, we recorded the health parameters and weight of animals in the control and trial group. Body weights were taken on the day birth, 15th, 40th, 60th and 90th. Farm veterinarians made the diagnosis of the diseases in the control and trial group.

Table 1. Average nutrient values of milk which used for calf feeding during the trial

\begin{tabular}{lr}
\hline Nutrients & $\%$ \\
\hline Dry Matter & 12.06 \\
Fat & 3.40 \\
Protein & 3.01 \\
Fat/Protein & 1.13 \\
MUN & 14.33 \\
Urea & 30.69 \\
Fat-Free Dry Matter & 8.47 \\
Casein & 2.24 \\
Lactose & 4.90 \\
Acetone & 0.11 \\
\hline
\end{tabular}

Statistical analysis: Independent samples T-test were used for the difference between control and trial group importance in terms of weights on birth, 15th day, 40th day, 60th day and 90th day. We used the Chi -square test to compare the health data of the control and trial group. It was used SPSS 13.0 statistical calculation program. Statistical significance was defined according to $P<0.05$. 


\section{Results}

It has provided the standard error measurements, significance levels and detected average calf weights of trial and control group on 15th, 40th, 60th and 90th days on Table 2 . There was no significant difference in the detected weight gains on birth and 15th days $(P>0.05)$. But on the 40th, 60th and 90th days weighing, the difference was significant $(P<0.05)$, (Table 2).

Table 2. Calf weights of trial and control group during the experiment $(n=20)$

\begin{tabular}{|c|c|c|c|c|c|}
\hline \multirow{2}{*}{$\frac{\text { Day }}{0}$} & \multicolumn{2}{|c|}{ Macleaya cordata } & \multicolumn{2}{|c|}{ Control } & \multirow{2}{*}{$\frac{P \text { Values }}{0.119}$} \\
\hline & 36.10 & \pm 1.24 & 38.90 & \pm 1.24 & \\
\hline 15 & 40.55 & \pm 1.16 & 43.41 & \pm 1.28 & 0.107 \\
\hline 40 & $53.63^{b}$ & \pm 1.01 & $58.18^{a}$ & \pm 1.12 & 0.004 \\
\hline 60 & $68.98^{b}$ & \pm 1.23 & $73.84^{a}$ & \pm 1.04 & 0.004 \\
\hline 90 & $83.30^{b}$ & \pm 1.34 & $98.82^{a}$ & \pm 0.54 & 0.000 \\
\hline
\end{tabular}

$a-b$ : The average values with different letters on the same line have significantly difference.

With the purpose to detect the MCE effect on calf health, we recorded the animals which have aspiration pneumonia, clinical pneumonia, chronic pneumonia, feed induced diarrhea and calf diarrhea in the trial and control group. A number of the sick calves in the trial and control group have shown on Table 3 according to disease type.

Table 3. Number of sick calves in the experimental and control groups according to disease type

\begin{tabular}{lccccc}
\hline & $\begin{array}{c}\text { Macleaya cordata } \\
(\mathrm{n}=20)\end{array}$ & $\begin{array}{c}\text { Control } \\
(\mathrm{n}=20)\end{array}$ & $\begin{array}{c}\text { Chi-Square } \\
P \text { Value }\end{array}$ \\
\cline { 2 - 6 } Disease & $\mathrm{n}$ & $\%$ & $\mathrm{n}$ & $\%$ & \\
\hline $\begin{array}{l}\text { Aspiration } \\
\text { Pneumonia }\end{array}$ & $0^{\mathrm{b}}$ & 0.0 & $4^{\mathrm{a}}$ & 2.0 & $4.444(0.035)$ \\
$\begin{array}{l}\text { Clinical } \\
\text { Pneumonia }\end{array}$ & $9^{\mathrm{b}}$ & 45.0 & $17^{\mathrm{a}}$ & 85.0 & $7.033(0.008)$ \\
$\begin{array}{l}\text { Chronic } \\
\text { Pneumonia }\end{array}$ & 3 & 15.0 & 3 & 15.0 & $0.000(1.000)$ \\
$\begin{array}{l}\text { Feed Induced } \\
\text { Diarrhea }\end{array}$ & 7 & 35.0 & 11 & 55.0 & $1.616(0.204)$ \\
Calf Diarrhea & 1 & 5.0 & 4 & 20.0 & $2.057(0.151)$
\end{tabular}

$a-b$ : The average values with different letters on the same line have significantly difference.

We recorded diseases, treatments, date of onset of disease and the date of treatment in trial and control group calves. SPSS cross- table rates of detected calf diseases in trial and control groups have shown in Table 4.
Table 4. SPSS cross-table rates of detected calves diseases in trial and control groups

\begin{tabular}{llcc}
\hline Disease & Group & \multicolumn{2}{c}{ Status } \\
\hline & & Patient (\%) & Healthy (\%) \\
\cline { 3 - 4 } Clinical & Macleaya cordata & 22.5 & 27.5 \\
Pneumonia & Control & 42.5 & 7.5 \\
& & & \\
Feed Induced & Macleaya cordata & 17.5 & 32.5 \\
Diarrhea & Control & 27.5 & 22.5 \\
& & & \\
Chronic & Macleaya cordata & 7.5 & 42.5 \\
Pneumonia & Control & 7.5 & 42.5 \\
\hline
\end{tabular}

In order to determine the risk of developing diseases whatever connect to MCE application, as a result of the chi-square test, the difference between the groups was founded significant in clinical pneumonia and aspiration pneumonia $(\mathrm{P}<0.05)$. However, there was no significant difference between the trial and control group which calves have feed induced diarrhea, chronic pneumonia and calf diarrhea $(\mathrm{P}>0.05)$.

\section{Discussion}

It has known the fact that using phytobiotics in animal nutrition, has positive effects on various performance parameters. In this study, there are no positive effect on 40th, 60th and 90th day weighings of calves weight despite applied MCE recommended dosages for 21 days (Table 1). Calsamiglia et al. (2007) shown that adding essential oil to milk replacer, decreases feed intake due to the flavor problems in the feed. In this study, due to the taste of MCE, it decreases of milk replacer intake observed. Therefore, the results obtained in this study in line with Calsamiglia et al. (2007)'s study results.

In many studies that applied different essential oils to ruminants, not determines significant statistical differences and was not observed positive results in terms of performance. In the study conducted by Santos et al. (2015) with applied essential oils in the milk replacer, not reported any change in feed consumption and calf weight. Vakili et al. (2013) applied $5 \mathrm{~g} /$ head/ day phytobiotic containing cinnamon and thyme to Holstein calves who have an average weight of $217 \mathrm{~kg}$ and reported no significant effect on daily weight gain, feed consumption and feed conversation ratio. The results obtained from these studies support our findings. 
There are also studies reporting that phytogenic ingredients have a positive effect on ruminants (Ruben et al., 2015). A study carried out by Estrada Angulo et al. (2016) in sheep during the finishing period on the use of MCE; not detected significant statistical differences in daily weight gains, despite reported that trial group which applied MCE provide $11 \%$ more weight gain than the control group.

Results of the studies on animal health of feed additives with phytogenic ingredients show differences. Bampidis et al. (2006) applied feed additives to black pied breed calves which have diarrhea. They applied oregano essential oil with dosage a $10 \mathrm{mg} /$ day/ kg BW to one group and applied neomycin sulfate as antibiotics with dosage $10 \mathrm{mg} /$ day/ kg BW. There was no difference in diarrheal days, diarrhea severity and mortality rate between thyme essential oil and antibiotic applied group. Unlu et al. (2011) detected that addition of $250 \mathrm{mg}$ oregano and garlic essential oils in to the full fat milk per day, did not cause any positive results on fecal coliform, Escherichia coli and Lactobacillus spp. numbers, fecal score and diarrhea treatment days. Liu et al. (2016) reported that no significant difference in performance when compared control group to the group which applied MCE for 90 days to weaned piglets $(P>0.05)$. But in the same study, the group with Macleaya

\section{Acknowledgments}

All trial materials were supplied by Phytobiotics Futterzusatzstoffe GmbH (Rosengasse 9, 65343 Eltville, Germany). The authors greatly express their appreciation to the staff (Veterinarian Melih ERTÜRK

\section{References}

Aguilar Hernández, J. A., Urías Estrada, J. D,. López Soto, M. A., Barreras, A., Plascencia, A., \& Montaño, M. (2016). Evaluation of isoquinoline alkaloid supplementation levels on ruminal fermentation, characteristics of digestion, and microbial protein synthesis in steers fed a high-energy diet. Journal of Animal Sciences, 94(1), 267-274.

Bampidis, V. A., Christodoulou, V., Florou - Paneri, P., \& Christaki, E. (2006). Effect of dried oregano leaves versus neomycin in treating new born calves with colibacillosis. Journal of Veterinary Medicine, 53(3), 154-156.

Calsamiglia, S., Busquest, M., Cadozo, P., Castikkejos, Estrada Angulo, A., Aguilar Hernández, A., Osuna Pérez, L., \& Ferret, A. (2007). Essential oils as modifiers of rumen microbial fermentation: a review. Journal of Dairy Science, 90(6), 2580-2595.

Chaturvedi, M. M., Kumar, A., Darnay, B., Chainy, G. B. cordata significantly increased volumes of ZO-1 and claudin-1, particularly in comparison with the pigs in the control group. Therefore researchers reported that MCE increases intestinal barrier function and can be used as an alternative to antibiotics for piglets (Liu et al., 2016). When we looked to the health results in our trial, in terms of aspiration and clinical pneumonia observed significant results in favor of MCE treated group $(P<0.05)$. However, there was no significant difference in feed induced diarrhea, chronic pneumonia and calf diarrhea $(P>0.05)$. These positive results weldable antimicrobial effect of the extract with based on Liu et al. (2016) reviews.

The results obtained in the study; MCE which use as a feed additive and added to milk replacer, has shown no positive effect on calf weight gain. When an evaluation is made in terms of health, MCE especially decreased the incidence of respiratory diseases. For this reason, MCE recommended for use as a preservative especially for the respiratory disease for the first stage of life.

In conclusion, MCE has the potential to decrease the incidence of respiratory diseases in calves. Future research is needed to determine the benefit of feeding MCE if it can be used as an alternative to antibiotics for suckling calves.

and Agricultural Engineer Onur DURGUN) of Uluova Dairy Farm for the use of their facilities and their assistance with veterinary care of the dairy calves.

N., Agarwal, S., \& Aggarwal, B. B. (1997). Sanguinarine (Pseudochelerythrine) is a potent inhibitor of NF-KB activation, IKB $\alpha$ phosphorylation, and degradation. Journal of Biological Chemistry, 272 (48), 30129-30134.

Dvǒrak, Z., Sovadinov'a, I., Bl'aha, L., Giesy, J. P., \& Ulrichov'a, J. (2006). Quaternary benzo[c] phenathridine alkaloids sanguinarine and chelerythrine do not affect transcriptional activity of aryl hydrocarbon receptor: analyses in rat hepatoma cell line H4IIE.luc. Food and Chemical Toxicology, 44 (9), 1466-1473.

M., Núñez Benítez, V. H., Castro Pérez, B. I., \& Silva Hidalgo, G. (2016). Influence of quaternary benzophenantridine and protopine alkaloids on growth performance, dietary energy, carcass traits, 
visceral mass, and rumen health in finishing ewes under conditions of severe temperature - humidity index. Asian-Australasian Journal of Animal Sciences, 29(5), 652-658.

Jeshari, M., Riasi, A., Mahdavi, A. H., Khorvash, M., \& Ahmadi, F. (2016). Effect of essential oils and distillation residues blends on growth performance and blood metabolites of Holstein calves weaned gradually or abruptly. Livestock Science, 185, 117122.

Kantas, D., Papatsiros, V. G., Tassis, P. D., Athanasiou, L. V., \& Tzika, E. D. (2015). The effect of a natural feed additive (Macleaya cordata), containing sanguinarine, on the performance and health status of weaning pigs. Animal Science Journal, 86(1), 9298.

Khadem, A., Soler, L., Everaert, N., \& Niewold, T. A. (2014). Growth promotion in broilers by both oxytetracycline and Macleaya cordata extract is based on their anti-inflammatory properties. British Journal of Nutrition, 112(7), 1-9.

Liu, G., Guan, G., Jun, F., Martínez, Y., Chen, S., \& Bin, P. (2016). Macleaya cordata extract decreased diarrhea score and enhanced intestinal barrier function in growing piglets. BioMedical Research International, 7 pages.

Liu, Y., Song, M., Che, T. M., Bravo, D., Maddox, C. W., \& Pettigrew, J. E. (2014). Effects of capsicum oleoresin, garlic botanical, and turmeric oleoresin on gene expression profile of ileal mucosa in weaned pigs. Journal of Animal Science, 92(8), 34263440.

Matulka, R. A., von Alvensleben, S., Morlacchini, M. \& Fusconi, G. (2018). Tolerance study for standardized Macleaya cordata extract added to chicken layer diet. Open Journal of Animal Sciences, 8(1), 104-117.

Namkung, H., Li, M., Gong, J., Yu, H. \& Cottrill, M. (2004). Impact of feeding blends of organic acids and herbal extracts on growth performance, gut microbiota and digestive function in newly weaned pigs. Canadian Journal of Animal Science, 84(4), 697 $-704$.

Newton, S.M., Lau, C., Gurcha, S.S., Besra, G.S. \& Wright, C.W. (2002). The evaluation of forty-three plant species for in vitro antimycobacterial activities: Isolation of active constituents from Psoralea corylifolia and Sanguinaria canadensis. Journal of Ethnopharmacology, 79(1), 57-67.

Ruben, B., Billy, J., Cervantes, I.R., Aljandro Plascencia, J., Alejandro, C. \& Marco, A. (2015). Supplementary levels of Macleaya cordata plant extract Sangrovit
RS on feedlot performance and carcass traits of finishing bullocks. American Dairy Science Association Ruminant Nutrition Beef I, Poster M 323.

Santos, F. H. R., De Paula, M. R., Lezier, D., Silva, J. T., Santos, G., \& Bittar, C. M. M. (2015). Essential oils for dairy calves: effects on performance, scours, rumen fermentation and intestinal fauna. Animal Consortium, 9(6), 958-965.

Ünal, A., \& Kocabağlı, N. (2014). Effect of different dosages of oregano oil on performance and some blood parameters in lambs. Veterinary journal of Ankara university, 61(3), 199-204.

Ünlü, H. B., \& Erkek, R. (2011). Effects of oregano and garlic essential oil on performance of calves, and some parameters of faeces and blood. PhD thesis, Ege University, Izmir, Turkey.

Vakili, A. R., Khorrami, B., Danesh Mesgaran, M., \& Parand, E. (2013). The effects of thyme and cinnamon essential oils on performance, rumen fermentation and blood metabolites in Holstein calves consuming high concentrate diet. Asian Australasian Journal of Animal Science, 26(7), 935 944.

Vieira, S. L., Oyarzabal, O. A., Freitas, D. M., Berres, J., Peña, J. E. M., Torres, C. A., \& Coneglian, J. L. B. (2008). Performance of broilers fed diets supplemented with sanguinarine-like alkaloids and organic acids. Journal of Applied Poultry Research, 17(1), 128-133.

Zhao, L., Von Alvensleben, S., Fusconi, G., \& Morlachini, M. (2017). Safety evaluation of a standardized Macleaya cordota extract in a ninety day feeding study in weaned piglets. Journal of Animal Sciences, 7, 213-231. 